\title{
O ensino por competências no México e o papel dos organismos internacionais
}

\author{
ADRIANO LARENTES DA SILVA \\ Instituto Federal de Santa Catarina, Chapecó, SC, Brasil
}

RESUMO

Este trabalho analisa a implantação do ensino por competências no México e a participação nesse processo de organismos internacionais como Banco Mundial, Organização Internacional do Trabalho, Organização das Nações Unidas para a Educação, a Ciência e a Cultura e Organização para a Cooperação e Desenvolvimento Econômicos. Baseia-se em pesquisa de campo realizada no México no Colégio Nacional de Educação Profissional Técnica e busca mostrar que os vínculos entre os governos, representantes do capital, organismos internacionais e instituições de ensino vêm construindo uma rede internacional de formação de força de trabalho, tendo como principal referência padrões nacionais e internacionais baseados em competências. Nesse processo, instituições como o Colégio Nacional de Educação Profissional Técnica convertem-se em verdadeiros laboratórios internacionais para a adaptação e a chamada tropicalização desses modelos educativos às realidades locais, servindo posteriormente também como seus multiplicadores para outros países e instituições educativas.

PALAVRAS-CHAVE

competências; organismos internacionais; educação e trabalho. 


\title{
THE ROLE OF INTERNATIONAL ORGANIZATIONS ON EDUCATION BASED ON COMPETENCIES IN MEXICO
}

\begin{abstract}
This paper analyzes the role played by international organizations such as the World Bank, the International Labour Organization, the United Nations Educational Scientific and Cultural Organization and the Organization for Economic Co-operation and Development in the implementation of teaching based on competencies in Mexico. The data were collected through field research conducted in Mexico, focusing on the National School of Technical Professional Education. The intention is to show how the links between governments, representatives of the capital, international organizations and educational institutions have been building an international network of training of the workforce, having as its main reference national and international standards based on competencies. In this process, institutions such as the National School of Technical Professional Education converted into true international laboratories that allow adaptation and the so-called tropicalization of these educational models to local realities, later serving also as its multiplier to other countries and educational institutions.
\end{abstract}

KEYWORDS

competencies; international organizations; education and labor.

\section{LA ENSEÑANZA POR COMPETENCIAS EN MÉXICO Y EL PAPEL DE LOS ORGANISMOS INTERNACIONALES}

\section{RESUMEN}

Este trabajo analiza la implementación de la enseñanza por competencias en México y la participación en ese proceso de las organizaciones internacionales como el Banco Mundial, la Organización Internacional del Trabajo, la Organización de las Naciones Unidas para la Educación, la Ciencia y la Cultura y la Organización de Cooperación y Desarrollo Económicos. La referencia para el análisis es el trabajo de campo realizado en México, lo cual si centró en el Colegio Nacional de Educación Profesional Técnica. El objetivo es mostrar cómo los vínculos entre los gobiernos, representantes del capital, las organizaciones internacionales y las instituciones educativas contribuyen para la construcción de una red internacional de capacitación de la fuerza laboral, basada en estándares nacionales e internacionales de competencias. En este proceso, las instituciones como el Colegio Nacional de Educación Profesional Técnica si convierten en verdaderos laboratorios internacionales que permiten la adaptación y la llamada tropicalización de estos modelos educativos a las realidades locales, además de servir también como multiplicador a otros países e instituciones educativas.

PALABRAS CLAVE

competencias; organizaciones internacionales; educación y trabajo. 


\section{INTRODUÇÃO}

Em setembro de 2014 dois acontecimentos no México ganharam as páginas dos jornais e tiveram grande destaque na imprensa local. $\mathrm{O}$ primeiro, que logo mobilizaria todo o país e chamaria a atenção também da imprensa internacional, envolvia o desaparecimento de quarenta e três estudantes da Escola Normal Rural Raúl Isidro Burgos, do município de Ayotzinapa, estado de Guerrero. O segundo envolvia estudantes de uma das mais conceituadas instituições de ensino superior e tecnológico do México, o Instituto Politécnico Nacional (IPN).

No primeiro caso, os envolvidos eram estudantes das classes populares, filhos de camponeses que haviam decidido seguir carreira como professores normalistas e estudavam em regime de internato em uma das escolas que ainda resistiam no meio rural mexicano. Construída em 1926, a escola Raúl Isidro, assim como outras escolas normais rurais do país, historicamente buscou aliar conhecimentos pedagógicos, técnicos e políticos, ficando conhecida por uma larga tradição de esquerda e como uma escola combativa e socialista.

Foi justamente por sua combatividade, por décadas de falta de investimentos do Estado nas escolas do meio rural e por sua oposição ao poder político local e nacional que os estudantes de Ayotzinapa acabariam sendo presos na noite do dia 26 de setembro e entregues pela polícia a narcotraficantes para serem brutalmente assassinados. Com esse episódio, revelava-se que a luta contra o narcotráfico, contra o Estado opressor, contra as injustiças e a favor de uma escola plural, politicamente transformadora, deveria continuar.

No mesmo dia do desaparecimento dos quarenta e três normalistas de Ayotzinapa, uma grande marcha de estudantes do IPN parou o centro da Cidade do México. Eram milhares de estudantes de diferentes carreiras que haviam saído às ruas para lutar contra a falta de democracia e a mudança nos planos e programas de estudo de sua instituição. O que estava em questão, segundo os estudantes, era uma profunda mudança que visava colocar o IPN a serviço de uma lógica de mercado, retirando disciplinas estratégicas e desqualificando suas formações profissionais.

Criado em 1936, com o lema "a técnica a serviço da pátria”, o IPN incorporou diversos tipos de escolas técnicas que funcionavam, até então, na Cidade do México, reunindo, segundo Weiss e Bernal (2013), duas grandes tradições de educação técnica: a das escolas de artes e ofícios e das escolas de engenharia. Logo se destacou pela qualidade com que formava engenheiros, arquitetos, médicos, cientistas sociais, entre vários outros profissionais. Agora, segundo os estudantes, com o discurso de "atualizar" a instituição, o que os gestores do IPN queriam na verdade era submetê-la à mesma lógica proposta pelas reformas educativas neoliberais das últimas décadas, as quais tiveram orientação e supervisão de diferentes organismos internacionais.

Os dois episódios relatados permitem várias reflexões, revelando os embates políticos e educativos contemporâneos em um país que tem sua história marcada por lutas e resistências, primeiro contra o domínio espanhol, a partir do século XVI, depois contra o domínio americano, a partir do século XIX, e atualmente contra o domínio do capital internacional. 
Ambas as instituições envolvidas surgiram no contexto posterior à Revolução Mexicana, iniciada em 1910 e que mobilizou as camadas populares especialmente nos anos seguintes, sob o comando de lideranças como Pancho Villa e Emiliano Zapata. Era um contexto em que a maioria da população ainda vivia no campo, mas que gradativamente foi abandonando suas terras para viver nas cidades ou migrar para os Estados Unidos. Nesse contexto, grande parte dos mexicanos não tinha acesso à escola ou tinha poucos anos de estudo. Era a fase da urbanização e industrialização aceleradas do país, que exigia escolas, universidades e ensino técnico no campo e nas cidades. Era também o tempo dos discursos sobre os benefícios da modernidade.

Conforme mostra Aguilar (2013), industrializar o país tornou-se a grande prioridade dos governos mexicanos nesse período, pois acreditava-se que a modernização do México dependia da multiplicação de fábricas, técnicos e operários e que as inovações e o desenvolvimento tecnológico advindos dessa nova fase de modernidade trariam benefícios para todos. Recuperado da grande crise de $1929 \mathrm{e}$ passados os efeitos da II Guerra Mundial, o sistema capitalista vivia sua fase áurea em nível internacional, como mostrou Hobsbawm (1995).

A partir dos anos de 1960, com o desenvolvimento econômico do país, o aumento populacional e as pressões por novas escolas, houve a expansão do ensino superior e foram criadas várias outras instituições de nível médio e ensino técnico, entre elas os Colégios de Bacharéis (COBACH) e os Centros de Bacharelado Tecnológico Industrial e de Serviços (CBTIS) e os Centros de Bacharelado Tecnológico Agropecuário (CBTA).

Nesse processo de expansão da oferta educativa no México estiveram historicamente em disputa distintas concepções de escola e modelos educativos. De alguma maneira seguiam vivos os princípios democráticos e laicos da Revolução Mexicana e os impactos da adoção de uma educação socialista, experimentada no governo de Lázaro Cárdenas, entre 1934 e 1940, mas também avançavam, especialmente no ensino técnico, as perspectivas tecnicistas e pragmáticas de educação. Com a crise econômica dos anos de 1970, essas perspectivas ganhariam ainda mais terreno, agora com o estímulo, o constructo teórico e o patrocínio de diferentes organismos internacionais.

Além disso, ao tecnicismo se somariam o construtivismo, a educação por objetivos e a teoria do capital humano. Conforme mostram Sacristán (1988), Frigotto (2006) e Ramos (2010), especialmente a partir dos anos de 1960 essas perspectivas educativas passaram a ser cada vez mais associadas aos discursos, aos interesses e à lógica de mercado e a estruturar as orientações dos organismos internacionais em busca de um modelo educativo internacional. Nesse contexto, aumentaram as pressões para que as instituições de ensino se aproximassem cada vez mais do setor produtivo e atendessem as suas demandas. Os discursos hegemônicos eram de que as formas tradicionais de oferta educativa, voltadas para a continuidade dos estudos no ensino superior, e o próprio formato da educação superior, precisavam ser mudadas. No caso mexicano, para atender a essas "novas demandas", uma das instituições que surgiu nesse período como alternativa às universidades e principalmente ao IPN foi o Colégio Nacional de Educação Profissional Técnica (CONALEP), destinado exclusivamente à formação de técnicos de nível médio. 
Criado no final dos anos de 1970, esse colégio se transformaria no grande laboratório de experimentação de novos modelos educativos, de contratação docente e de relações entre a escola e o setor produtivo. A partir dele seriam gestadas e adaptadas concepções educativas propostas por organismos internacionais como a Organização das Nações Unidas para a Educação, a Ciência e a Cultura (UNESCO), Banco Mundial, Organização Internacional do Trabalho (OIT) e Organização para a Cooperação e Desenvolvimento Econômicos (OCDE). Depois de gestadas e tropicalizadas, essas concepções seriam aplicadas às outras instituições de ensino nacionais e internacionais. Foi assim que uma dessas perspectivas, a da educação por competências, ganhou terreno no México a partir de 1992 e estendeu-se à grande maioria dos programas de bacharelados mexicanos, em 2008, e a outros sistemas e níveis de ensino com as reformas educativas de 2012 e 2013.

Era contra essas concepções pragmáticas e mercadológicas e suas consequências e por uma educação pública, gratuita e de qualidade que lutavam os estudantes de Ayotzinapa e do IPN, em setembro de 2014.

O presente trabalho analisa a implantação do ensino por competências no México, mostrando o papel desempenhado nesse processo por organismos internacionais como Banco Mundial, OIT, UNESCO e OCDE. A análise baseia-se em pesquisa de campo realizada no México entre setembro de 2014 e fevereiro de 2015, tendo como foco o CONALEP, instituição que está atualmente entre as que possuem o maior número de educandos no ensino técnico no México e que foi a pioneira na adoção e implantação da pedagogia das competências nesse país.

Na pesquisa de campo foram entrevistados diretores, equipes técnicas, docentes e estudantes dessa instituição. Para a realização das entrevistas usou-se como referência a metodologia da história oral (Alberti, 2005; Portelli, 1993), aproveitando-se de suas grandes contribuições para a área da educação (Silva, 2014). Também foi realizada análise documental em diferentes bibliotecas e centros de documentação, visando compreender as políticas públicas para a educação profissional no México a partir da década de 1970 e as transformações ocorridas no CONALEP após 1992 com a adoção da pedagogia das competências.

Com base na experiência dessa instituição, a intenção é mostrar como os vínculos entre os governos, representantes do capital, organismos internacionais e instituições de ensino vêm construindo uma rede internacional de formação de força de trabalho, tendo como principal referência padrões nacionais e internacionais baseados em competências.

Como o Brasil faz parte dessa rede internacional, conhecer a experiência do México, um país latino-americano e de capitalismo periférico como o nosso, é importante para compreendermos o processo internacional do capital, que tem na superexploração dos trabalhadores a sua lógica.

Nesses termos, identificar no México a atualidade das reformas que aqui no Brasil se processaram de forma explícita e intensa na década de 1990, que seguiram vivas em governos municipais e estaduais nos anos 2000 e que foram retomadas em nível federal a partir do impeachment da presidente Dilma Rousseff, em 2016, nos ajuda a compreender como se estrutura o que Shiroma (2011) chamou de "redes sociais de hegemonia", e que Dale (2004) identificou como uma "agenda 
globalmente estruturada para a educação", pautada na hegemonia do pensamento empresarial que, direta ou indiretamente, ocupam o Estado e convencem a sociedade civil, dando orientações concretas às políticas educacionais de hoje.

\section{O CONALEP E AS INFLUÊNCIAS DOS ORGANISMOS INTERNACIONAIS NO MÉXICO}

Criado em dezembro de 1978, o CONALEP é hoje uma instituição consolidada, com uma oferta educativa em todo o território nacional mexicano.

Em 2014 possuía mais de trezentos mil estudantes e dezesseis mil docentes em trezentas e nove unidades de ensino conhecidas como plantéis (CONALEP, 2015), ofertando principalmente cursos de educação média superior (equivalente ao ensino médio no Brasil) para jovens, que em sua grande maioria tinham entre 15 e 17 anos (CONALEP, 2012). Os cursos ofertados distribuíam-se em distintas áreas, com destaque para o setor industrial e de serviços, e estavam organizados para a conclusão simultânea da formação propedêutica e da formação técnica em seis semestres.

A criação do CONALEP foi fortemente influenciada pelo contexto mexicano e mundial da década de 1970, principalmente pela crise mundial do petróleo de 1973 e pelas expectativas econômicas criadas no México com as descobertas de petróleo no Golfo do México no final dessa mesma década. Como relatou um dos entrevistados durante o trabalho de campo, em 2014, os discursos oficiais com as novas descobertas de petróleo eram de que o México não seria mais um país pobre e que era preciso se preparar para administrar a abundância dessa nova era. A euforia, no entanto, duraria até 1982, quando uma grave crise econômica atingiu o país e mostrou que o sonho de um México rico e próspero não havia se efetivado conforme prometido.

Além do momento econômico favorável e da justificativa de que era necessária uma instituição técnica para preparar o país para o crescimento esperado, a criação do CONALEP também foi uma resposta do governo mexicano às recomendações da UNESCO para a educação técnica. Entre os principais documentos orientadores nesse sentido estão as recomendações da $18^{a}$ Conferência Geral da UNESCO, realizada em Paris em 1974. Segundo o documento final dessa conferência, publicado em 1975: "Dada la necesidad de establecer nuevas relaciones entre la educación, la vida laboral y la comunidad en general, la enseñanza técnica y profesional debería formar parte de un sistema de educación permanente adaptado a las necesidades de cada país concreto" (UNESCO, 1975, p. 162). Além disso, esse sistema deveria procurar "abolir las barreras entre los niveles y las esferas de la educación, entre la enseñanza y el empleo, y entre la escuela y la sociedad", visando integrar o ensino técnico, profissional e geral em todos os ramos da educação pós-primária, "creando estructuras educativas abiertas y flexibles", levando em conta as necessidades de educação das pessoas e a evolução das profissões e dos empregos (UNESCO, 1975, p. 162-163). Nesse documento, a UNESCO enfatiza a importância de uma sólida formação básica associada ao ensino técnico, mas também busca reforçar o papel do ensino técnico para uma nova relação entre a escola, o setor produtivo e 
o emprego, destacando especialmente o caráter flexível que essas formações devem adotar. Além disso, segundo a UNESCO (1975, p. 167):

Deberían tomarse medidas especiales en relación con los jóvenes desempleados que no asisten a la escuela y con los hijos de trabajadores emigrados que sólo tienen un mínimo de enseñanza primaria o que carecen de ella, así como con los que no ingresan en programas de enseñanza o formación después de haber terminado la escuela obligatoria, a fin de que puedan adquirir conocimientos prácticos que les ayuden a conseguir un empleo.

Isto é, para os filhos de trabalhadores, emigrantes, jovens excluídos dos sistemas de ensino e da própria sociedade, assim como para os que haviam concluído o ensino primário (obrigatório), justificava-se uma formação restrita, "prática", direcionada ao emprego. Aqui, mais uma vez repete-se o discurso reforçado a partir da proletarização e do processo de exclusão social provocados pela Revolução Industrial, no século XVIII, de que era preciso ocupar as "classes perigosas" (Chalhoub, 2005), evitando que caíssem nos "vícios", que se envolvessem com a delinquência ou em distúrbios sociais. Em síntese, acreditava-se que por meio do ensino técnico se poderia direcionar esses grupos para o trabalho, controlando-os individual e coletivamente. Esse havia sido um dos principais propósitos das escolas de artes e ofícios e que se mantinha nos projetos subsequentes de ensino técnico.

De acordo com García, Camacho e Álvarez (2014), as recomendações da UNESCO, em especial as de 1974, são fundamentais para conhecer a origem e a evolução do sistema CONALEP. Uma das características dessa instituição foi ter nascido com um caráter eminentemente técnico, direcionada às classes populares $\mathrm{e}$ à formação de trabalhadores para o mundo do trabalho. Entre 1978 e 1997, ofertava ensino técnico em carreiras terminais, destinadas à formação de força de trabalho para a indústria e outros setores nacionais. Isso significava que os jovens e adultos que escolhiam esse colégio não teriam possibilidades de seguir para o ensino superior e deveriam ser encaminhados diretamente da escola para o mundo do trabalho. ${ }^{1}$ Tratava-se, portanto, de uma perspectiva que reforçava o caráter dual da educação profissional e da formação para os trabalhadores, com uma existência de uma escola para as classes populares (nesse caso técnica) e outra para os que tivessem condições de seguir para o ensino superior.

Havia sido contra esse modelo educativo dual, com uma formação para os que pensam e dirigem os sistemas produtivos e outra para os que executam o trabalho, que Gramsci (1982) propôs que se avançasse rumo à "escola unitária", uma escola não fragmentada e capaz de aproximar formação humanística, técnica e política. No entanto, o debate sobre a "escola unitária", bastante significativo no Brasil especialmente desde os anos de 1980, parece que, apesar das experiências

1 A oferta de formação propedêutica simultaneamente ao ensino técnico teve início em 1997 e se fortaleceu em 2003, quando foi criada a formação de técnico bacharel, e, consolidou-se em 2008, com a Reforma Integral da Educação Média Superior (RIEMS). 
socialistas anteriores e da influência da vertente politécnica francesa (Weiss e Bernal, 2013), não se constituiu como proposta alternativa e contra-hegemônica para a educação dos trabalhadores no México. Nesse país, ao menos no CONALEP, o que predominou na década de 1980 foi o tecnicismo e a perspectiva condutivista dos objetivos e, a partir dos anos de 1990, um novo pragmatismo manifestado pela pedagogia das competências.

De acordo com Ramos (2010, p. 205), a pedagogia das competências tem em sua matriz constituinte elementos do condutivismo, do funcionalismo e do construtivismo piagetiano e, aplicada à educação profissional, "adequa-se plenamente aos princípios tayloristas-fordistas de trabalho". No entanto, também dialoga diretamente com a lógica dos padrões flexíveis de produção valendo-se de uma perspectiva (neo)pragmática e (neo)tecnicista. Conforme Ramos (2011, p. 39), especialmente a partir dos anos de 1990, a noção de competências visou, entre outros aspectos, "reordenar conceitualmente a compreensão da relação trabalho-educação", "institucionalizar novas formas de educar/formar os trabalhadores e de gerir o trabalho" e "formular padrões de identificação da capacidade real do trabalhador para determinada ocupação". Desde esse período, segundo a autora, buscou-se dar materialidade a um conceito que possui múltiplas dimensões e que surgiu dos novos padrões produtivos em substituição ao conceito de qualificação.

Segundo Sacristán (2011,p. 14), existem alguns traços comuns que definem as competências, entre os quais se destacam:

- a reação às aprendizagens academicistas e às práticas educativas tradicionais;

- uma ênfase em aprendizagens práticas e úteis; e

- a busca de uma educação funcional.

Além disso, incorporadas às políticas educacionais, as competências vinculam-se, de acordo com Sacristán (2011, p. 14),

formulações que pretendem ser uma espécie de narrativa de emergência para salvar a insuficiente e inadequada resposta dos sistemas escolares às necessidades do desenvolvimento econômico, para controlar a eficiência dos cada vez mais custosos sistemas, objetos de um fracasso escolar persistente.

De acordo com o mesmo autor, as tentativas de adaptação dos modelos educativos ao mercado marcaram as políticas educacionais das décadas de 1980 e 1990, porém, desde esta última década, tais políticas "precisaram de outras linguagens, outros discursos, para se legitimar e se tornar mais apresentáveis e merecedoras de crédito" (Sacristán, 2011, p. 20). É nesse cenário que ganhou cada vez mais espaço a pedagogia das competências em todo o mundo.

Analisando as competências no contexto mexicano, Díaz Barriga (2006, p. 14) mostra que essa perspectiva chegou a esse país associada à ideia de inovação da educação e foi aplicada inicialmente no âmbito da formação profissional. "La novedad con el enfoque de las competencias radica en una puntualización minuciosa de los aspectos en los cuales se debe concentrar 'el entrenamiento' o 'la enseñan- 
za”. Para esse autor, ao aplicar essa perspectiva no contexto mexicano, acabou-se mesclando elementos contraditórios, de um lado estabelecendo uma formulação de "alta integração" por meio de competências gerais e, por outro, desdobrando os conhecimentos em diversas competências menores que, segundo ele, "fácilmente decaen en una propuesta de construcción curricular por objetivos fragmentários" (Díaz Barriga, 2006, p. 15). Em sua opinião, mesmo com as primeiras experiências desde os anos de 1990, não existia ainda, até meados dos anos 2000, uma formação curricular segura e uma proposta clara e definida sobre o uso do enfoque das competências no campo educacional mexicano. Apesar disso, o discurso sobre as competências já havia ocupado o debate educacional e se incorporado às políticas públicas de educação naquele país (Díaz Barriga, 2006).

A perspectiva das competências foi experimentada, adaptada e incorporada ao sistema de ensino mexicano a partir de 1992 pelo CONALEP, fortalecendo-se a partir de 1995, com o Conselho Nacional de Normalização e Certificação de Competências Laborais (CONOCER), e posteriormente, desde 2008, estendendo-se a outros bacharelados de ensino médio, com a RIEMS, chegando atualmente também aos demais níveis e modalidades de ensino. Em 2014, estava presente em projetos, planos e programas da educação infantil até a pós-graduação, em instituições públicas e privadas.

Para que tivesse êxito no contexto mexicano, essa nova perspectiva contou com investimentos financeiros nacionais e internacionais, por meio de um empréstimo concedido pelo Banco Mundial ao governo do México em 1994. Esse empréstimo, como mostrou Centeno (1997), era de 265 milhões de dólares e tinha o objetivo de melhorar a qualidade da educação técnica e a capacitação no México visando satisfazer as necessidades do setor produtivo, estabelecendo um novo sistema de competências estandardizadas e de certificação e incrementando um sistema flexível de capacitação e a participação do setor privado na promoção e desenho dos novos cursos. Uma das instituições receptoras desses recursos foi o CONALEP, que também foi o principal local onde se realizaram as primeiras experiências para a implantação das competências em colaboração com o CONOCER. Com esses recursos, foi possível ao colégio conhecer experiências de outros países e contratar assessores internacionais especialistas em competências.

Conforme mostrou Garcia (2012, p. 53), esse não havia sido o primeiro empréstimo recebido pelo colégio por meio do governo mexicano, mas o terceiro. De acordo com esse autor, documentos disponíveis indicam uma "estreita colaboração" entre o governo do México e o Banco Mundial para o desenvolvimento do próprio projeto que culminou com a criação do CONALEP, em 1978, para a concessão do primeiro empréstimo, em 1981, e para o segundo, em 1985. Esses empréstimos serviram para construir e equipar distintos plantéis, ampliando a oferta educativa do colégio em todo o país. $\mathrm{O}$ argumento utilizado nesse momento pelo governo mexicano era a necessidade que existia de formação de técnicos de nível médio e a inadequada formação que recebiam os estudantes mexicanos até então. Em mensagem escrita em maio de 1983, o presidente da República, Miguel de la Madrid, enfatizava: 
Vivimos tiempos de cambio y reto; de crisis interna y externa; de incertidumbre; de competencia aguda y desordenada entre diversos países, algunos por mantener hegemonías, otros por sobrevivir, y la mayoría por encontrar una posición en la nueva configuración internacional en gestación que les permita subsistir como entidades soberanas y apoyar su desarrollo económico y social. El país se encuentra en un momento decisivo para la historia nacional; está de por medio el destino de la Nación. (México, 1983, p. 9)

Segundo Miguel de la Madrid, diante desse contexto, as instituições de ensino nacionais, especialmente as de ensino técnico e tecnológico, não se poderiam manter indiferentes às demandas do sistema produtivo.

La educación tecnológica deberá lograr una mayor coordinación y flexibilidad para adaptarse con relativa facilidad a las exigencias de su entorno. Deberá formar cuadros medios para la industria y proporcionar además los elementos técnicos y organizativos que requiere el país. (México, 1983, p. 227)

As saídas sugeridas e os discursos do governo mexicano nesse momento indicavam, portanto, que aos poucos as recomendações dos organismos internacionais estavam sendo incorporadas às políticas públicas do país.

A estratégia do Banco Mundial nesse momento em relação ao caso mexicano vinculava-se a uma perspectiva mais ampla, voltada à construção de um novo modelo educativo em nível global que materializasse a teoria do capital humano no âmbito da educação profissional e colocasse as distintas formações a serviço dos novos padrões produtivos e da cada vez mais acirrada concorrência internacional entre as empresas. A partir do fim dos anos de 1980, essa estratégia vinculava-se também ao Consenso de Washington, com a adoção do receituário neoliberal em todo o mundo e com o reordenamento político e econômico internacional a partir da queda do Muro de Berlim, em 1989.

Como parte de sua estratégia, o Banco Mundial lançou, em 1991, em língua inglesa e, em 1992, em língua espanhola, o documento de política do Banco Mundial, em que projetou qual deveria ser a perspectiva de educação técnica e profissional a partir de então nos países "em desenvolvimento".

Segundo esse documento, na nova ordem internacional, os países em desenvolvimento necessitariam aumentar a produtividade de suas empresas se quisessem competir com êxito em uma era de rápidas mudanças econômicas e tecnológicas.

Esto requiere no sólo inversiones de capital sino también una fuerza laboral que tenga la flexibilidad necesaria a fin de adquirir distintas calificaciones para trabajos nuevos a medida que las estructuras de las economías y las ocupaciones cambian. (Banco Mundial, 1992, p. 7)

De acordo com o Banco Mundial, para formar trabalhadores mais flexíveis eram necessárias também instituições de ensino técnico flexíveis, abertas a ajustes em seus planos e programas de estudo, adaptando-os à nova realidade do mercado. Para o banco, as instituições mais abertas e ajustadas a essas mudanças seriam as 
instituições privadas, geridas pelos próprios empresários, as quais deveriam ser incentivadas pelo poder público, já que seu alcance ainda era bastante limitado, o que exigiria um período de transição e um protagonismo dos governos dos países mais empobrecidos.

Especialmente en los países de ingreso bajo, los gobiernos tendrán que seguir financiando y brindando capacitación en el futuro inmediato, pero este papel debe evolucionar hacia una función de fomento constante de la capacidad de adiestramiento de los empleadores y demás proveedores del sector privado. Esto es un proceso largo y, por lo tanto, requiere política que compensen las limitaciones de dicho sector durante el período de transición. (Banco Mundial, 1992, p. 8)

Para o Banco Mundial, além do estímulo à capacitação pelo setor privado, as políticas de capacitação profissional teriam êxito se:

- houvesse, por parte dos estados, o fortalecimento da educação primária e secundária;

- a melhora da "eficácia e eficiência" da capacitação do setor público;

- a capacitação estivesse vinculada a outros programas voltados aos grupos mais pobres e socialmente desfavorecidos.

E, para que não houvesse dúvidas sobre seus propósitos, o banco advertia que essas políticas tinham "consecuencias importantes para la ayuda internacional" e que, para a consessão de novos financiamentos, seria mais rigoroso quanto aos resultados esperados (Banco Mundial,1992, p. 24). Essa, aliás, constituiu-se e ainda se constitui em uma das marcas históricas do Banco Mundial, ou seja, obrigar os países pobres a cumprir o seu receituário por meio de financiamentos e da liberação de recursos aos já endividados governos.

Conforme mostrou Chávez (2000), as condições para ter acesso aos financiamentos internacionais, estas incluídas nos programas de ajuste desde os primeiros empréstimos, a partir da crise financeira do início dos anos de 1980, obrigaram o governo mexicano a adotar as políticas encaminhadas pelos organismos internacionais para assentar as bases de um novo modelo de desenvolvimento. Esse novo modelo, pautado em uma maior abertura do país ao capital internacional, havia sido explicitado nos Planos Nacionais de Desenvolvimento de 1983 e 1988 e, neste último ano, também pelo Programa Nacional de Modernização Educativa, visando preparar o México para o novo contexto internacional e especialmente para o Tratado de Livre Comércio com os Estados Unidos e Canadá, a partir de 1994.

Segundo Chávez (2000), em 1994, primeiro ano do Tratado de Livre Comércio, o México era um país em que se haviam aprofundado as diferenças sociais, depois de mais de uma década de políticas empreendidas para abertura ao capital estrangeiro e às novas tecnologias e de transformações profundas nos sistemas produtivos e estruturas laborais. Nesse momento, era cada vez mais repetido internamente os discursos dos organismos internacionais sobre a importância da flexibilidade do trabalho e da qualificação profissional para a competividade do 
país em nível global. Ao mesmo tempo, reduzia-se o poder de enfrentamento dos sindicatos e aumentava o trabalho temporário, subcontratado e precário.

É, portanto, nesse cenário que estão as primeiras experiências do CONALEP voltadas a uma educação flexível ajustada à realidade mexicana e aos discursos de modernização e de competitividade internacional. Segundo alguns dos entrevistados, os primeiros ajustes nos planos e programas de estudo iniciaram no fim dos anos de 1980, mas foi na década de 1990 que o colégio iniciou a chamada "tropicalização das competências" no México.

\section{O PROCESSO DE “TROPICALIZAÇÃO DAS COMPETÊNCIAS” NO MÉXICO}

Presente atualmente em todo o mundo, o conceito de tropicalização faz parte dos discursos e estratégias de diferentes empresas multinacionais, as quais buscam adaptar seus produtos às realidades de cada país.

No ramo automobilístico, por exemplo, é recorrente o conceito de "tropicalização de carros", com ajustes de modelos, peças e características de um veículo à realidade física, cultural e social de determinadas regiões do planeta. Além de veículos, há também a tropicalização de comidas, de produtos, de projetos arquitetônicos, de sementes e espécies e da própria publicidade. Em todos esses casos, tropicalizar significa adaptar, ajustar, aclimatar, criar identidade e reconhecimento local, visando a uma aceitação e incorporação desses produtos e serviços no cotidiano de cada região ou país.

Na lógica de mercado, com predomínio cada vez maior de produtos e serviços globalizados, tropicalizar é uma maneira de as empresas tentarem posicionar-se de forma diferente em relação a outras empresas concorrentes e diante de consumidores com exigências, condições sociais, culturais e econômicas específicas. Nesse sentido, a tropicalização é parte das novas estratégias do capital em nível internacional e está perfeitamente ajustada aos padrões flexíveis de produção, que substituíram a produção fordista, padronizada e em série. É essa mesma lógica que tem sido mobilizadora da "tropicalização das competências" em todo o mundo e, a partir dos anos de 1990, também no México. Ao que parece, trata-se de uma lógica de tropicalização controlada, docilizada, domesticada e subordinada ao capital internacional.

No caso mexicano, a tropicalização das competências contou com o apoio e incentivo do Banco Mundial e foi inspirada nos modelos estadunidense, canadense, inglês e australiano. De todos, o que predominou foi este último, a partir do fim dos anos de 1990, com a contratação de assessores australianos, entre eles Andrew Gonczi, professor da Universidade de Sidnei. ${ }^{2}$ Como um grande conhecedor das

2 Conforme mostra Ramos (2011, p. 99), o modelo de competências australiano apresenta uma abordagem holística ou integrada, "que pretende combinar o enfoque de atributos gerais com o contexto em que se aplicam”. Segundo essa autora, o que difere esse dos demais modelos é a preocupação com o marco curricular, o que faz com que se afaste do funcionalismo inglês e se aproxime do construtivismo francês. 
competências e reconhecido internacionalmente nessa área, Gonczi encontrou no então diretor do CONALEP, Antonio Argüelles, intelectual mexicano com bastante entusiasmo e trânsito no governo federal para levar adiante a implantação das competências nesse país. Argüelles foi diretor do CONALEP entre 1995 e 2000, mas antes disso havia trabalhado no governo federal na Secretaria de Comércio e Fomento Industrial, atuando como partícipe e intelectual do novo processo modernizador do México.

Para legitimar e poder realizar as mudanças necessárias para a implantação das competências no México, um dos primeiros passos foi fazer um amplo estudo sobre as carreiras em que seriam feitas as provas-piloto a partir de 1994 e criar o CONOCER, em 1995. Outra etapa importante foi reunir, em 1996 e 1997, docentes, líderes sindicais e empresários para opinar sobre o que deveria ser mudado e, por fim, iniciar a implantação das mudanças no final dos anos de 1990. Desde então, tanto os docentes quanto os representantes dos trabalhadores seriam muito pouco solicitados a opinar, pois os novos projetos e planos de curso não passavam mais por suas mãos, uma vez que estavam concentrados em órgãos centrais e nos chamados desenhadores de currículo. Os únicos que seguiriam sendo ouvidos com regularidade seriam os empresários e seus representantes.

Como mostra Díaz Barriga (2009), as mudanças na forma como se constroem planos e programas de estudo ocorreram ao longo do século XX e vinculam-se diretamente à ascensão de uma pedagogia pragmática e do controle, inspirada no taylorismo, em que cada vez mais o acadêmico e a dimensão intelectual do trabalho docente vão dando lugar a uma visão administrativa, de gestão, na qual ganha poder uma série de especialistas. Nesse processo, já não há mais margem para currículos alternativos, mas o que se sobressai é a busca por um currículo único, nesse caso pautado em padrões internacionais baseados em competências.

Trata-se, portanto, de um processo que mescla um sistema de centralização, visando à construção de currículos flexíveis, com a taylorização do trabalho docente, retirando sua autonomia e limitando sua tarefa criativa. No caso mexicano e do CONALEP, essa mescla esteve associada a um sistema de contração flexível, em que os docentes foram e continuam sendo contratados por horas, como prestadores de serviço, com cargas horárias que não podem exceder as vinte horas semanais, pois uma das exigências desde a criação do colégio era que os docentes estivessem atuando também no setor produtivo. No processo de implantação das competências, vão ser esses mesmos docentes, taylorizados, que serão os principais responsáveis por implantar um modelo educativo que deve preparar para as mudanças no mundo do trabalho e que está focado na formação para ocupações flexíveis. Explicita-se nesse caso a versão tropicalizada das competências, que mescla elementos do construtivismo e do neopragmatismo, discursos sobre a necessidade de adaptação à nova lógica de mercado e estruturas curriculares flexíveis com a precarização do trabalho, o neocondutivismo, a centralização dos planos e programas de curso e o controle sistemático do trabalho docente, no que poderíamos chamar de neotaylorismo, ou um taylorismo piorado e em versão tropicalizada e mais perversa. 
De forma geral, com a educação por competências o colégio estreitou ainda mais suas relações com o setor empresarial, adaptando seus planos e programas de estudo às demandas do mercado e aos novos padrões produtivos internacionais, conforme previa o receituário do Banco Mundial.

Em articulação com o governo mexicano e apoio dos organismos internacionais, o colégio ampliou, a partir dos anos de 1990, suas relações internacionais, realizando convênios com países centro-americanos, mas também com a Espanha, especificamente com a rede hoteleira espanhola em sua estratégia de ampliação dos mercados na América Latina e, no caso do México, nos estados de Chiapas e Quintana Roo, onde se localizam importantes sítios históricos maias e cidades litorâneas, como Cancun e Praia de Carmem.

Essa política de vinculações internacionais segue hoje em dia, mais recentemente com os novos vínculos com a Alemanha, para a realização do modelo de formação dual e, com os acordos com o Japão, para a formação de trabalhadores na área automotriz. Como observou um dos entrevistados durante o trabalho de campo, sempre depois de um convênio de cooperação técnica e educativa vêm acordos econômicos. Segundo outro entrevistado, para o capital internacional, o México é um país estratégico para o acesso a dois dos mais importantes mercados consumidores mundiais, os Estados Unidos e a América Latina. Parece ser essa lógica que move, por exemplo, as empresas automobilísticas alemãs e japonesas, que têm no CONALEP um importante aliado para a formação da força de trabalho requerida, já que é uma instituição que está disposta a adaptar-se às suas exigências.

Em geral, é por meio das relações internacionais que a instituição tenta, há vários anos, mudar sua imagem no México, bastante marcada pela oferta de carreiras terminais, mantendo-se política e financeiramente e também se vinculando de maneira efetiva a uma rede internacional de formação de força de trabalho e de certificação, em relação com governos e empresas multinacionais, mas também com outras instituições educativas vinculadas ao Centro Interamericano para o Desenvolvimento de Conhecimento em Formação Profissional (CINTERFOR), da OIT e outros organismos internacionais, recebendo e ofertando formação a professores, estudantes e equipes técnicas. A partir do CINTERFOR, o colégio estreitou nas últimas décadas, por exemplo, relações com o Serviço Nacional de Aprendizagem Industrial (SENAI) do Brasil e o Serviço Nacional de Aprendizagem (SENA) da Colômbia, para onde enviou equipes técnicas, professores e estudantes para receber formações pedagógicas e conhecer seus modelos educativos. Ao mesmo tempo, com o apoio da Secretaria de Relações Exteriores do México, o colégio assinou acordo de cooperação com o Colégio Vocacional de Artes e Ofícios da Costa Rica (COVAO), passando a oferecer formação pedagógica e transferindo seus conhecimentos e seu modelo tropicalizado de competências.

Todas essas vinculações permitiram ao colégio manter e aprofundar sua política educativa, servindo como um laboratório internacional e latino-americano de novas propostas educativas na lógica do mercado e do capital. Trata-se, no entanto, não apenas de um espaço de recepção e acolhimento de novas ideias, mas de adaptação, tropicalização, aplicação e difusão de conhecimentos sobre a formação de trabalhadores. 


\section{A OCDE E A BUSCA DE UM PADRÃO EDUCATIVO INTERNACIONAL}

A partir da década de 1990, outro organismo que teve grande influência para a difusão das competências no México foi a OCDE, que foi aos poucos ocupando o lugar de organizações como a UNESCO, aperfeiçoando os mecanismos e instrumentos de persuasão de líderes governamentais e intelectuais mexicanos e de outros países.

A entrada do México na OCDE ocorreu em 1994 e respondeu a interesses estratégicos, geopolíticos e de mercado dos países mais desenvolvidos. No México está o Centro Regional da OCDE para a América Latina, cuja finalidade principal é aumentar a visibilidade da organização na região e promover seu trabalho e suas atividades, estabelecendo contato com criadores de políticas, especialistas, líderes empresariais, universidades e representantes da sociedade civil (OCDE, s.d.). Segundo a OCDE, entre os benefícios do ingresso do México nessa organização está o fato de que as políticas públicas mexicanas em distintos âmbitos podem ser comparadas com experiências exitosas em esfera internacional (OCDE, s.d.).

Conforme mostra Sacristán (2011), a comparação entre os países é uma marca da OCDE, que se especializou em sistemas de avaliação internacional, destacando-se pela realização de provas, como as do Programa Internacional de Avaliação de Estudantes (PISA), gerando com essas provas seus relatórios e também suas recomendações aos governos.

De acordo com Lundgren (2013), as provas do PISA dão continuidade a sistemas de avaliação educativa que se fortaleceram no período posterior à Segunda Guerra Mundial, com a corrida espacial e a ascensão da teoria do capital humano como modelo a ser seguido. Cada vez mais, com as crises do capitalismo, aumentaram as pressões por uma maior eficiência e produtividade dos sistemas educativos, definindo-se metas e sistemas padronizados de avaliação e controle. No entanto, além de obter dados e subsídios sobre os processos educativos, esses novos sistemas de avaliação, ainda segundo Lundgren (2013), serviram e servem para ampliar o poder político e econômico dos países mais ricos.

Nessa busca pela avaliação dos resultados, a referência utilizada passa a ser a educação por competências. Para Sacristán (2011, p. 24), "estamos diante de uma proposta que tem a pretensão de tornar as competências básicas norma universal a ser seguida, em todos os países e idades". Nesse processo, uma das tarefas da OCDE é também auxiliar os governos na implantação e acompanhamento de novas políticas educativas.

No caso do México, para dar legitimidade às reformas propostas, a OCDE, assim como já haviam feito anteriormente outras organizações internacionais, buscou aproximar-se da Secretaria de Educação Pública (SEP) utilizando-se de inúmeros estudos e diagnósticos, contratando para tal assessores ligados a renomadas instituições nacionais e internacionais.

Como mostra Plá (2014, p. 41-42), no processo de reformas educativas:

la relación entre los ministerios y los organismos internacionales no se da de la manera unilateral en la que los grandes intereses internacionales se imponen de manera cuasi natural sobre las naciones, sin resistencias o sin participaciones activas y creativas por parte de los distintos actores de la reforma. 
Isto é, há, na maioria das vezes, colaboradores e atores nacionais e locais que contribuem para materializar as propostas desses organismos. Essa lógica fica clara nos próprios documentos da OCDE, como no Acuerdo de cooperación México-OCDE para mejorar la calidad de la educación de las escuelas mexicanas (OCDE, 2010), em que essa organização, a pedido do governo do México, faz uma série de recomendações e até mesmo propõe um guia para a implementação prevendo as participações locais.

Con el fin de lograr la transmisión desde la OCDE hacia México, es necesario que un grupo nacional de actores reflexione, se "apropie" de las recomendaciones y las adapte. Resulta absolutamente esencial que todos los actores participen como socios legítimos y responsables en la implementación de estas recomendaciones. (OCDE, 2010, p. 7)

Entre esses "atores" e "sócios" da OCDE, deveriam estar no "comitê de trabalho para a implementação”, entre outros, os responsáveis pelas políticas públicas e membros "altamente respeitados" da academia.

Para reflejar y proponer estrategias de implementación, el comité debería estar compuesto por los responsables de generar políticas educativas, por miembros de la academia altamente respetados, por docentes, así como por personalidades del sector público y de la sociedad civil. (OCDE, 2010, p. 8)

Trata-se, portanto, de um processo colaborativo, consentido e politicamente muito bem planejado. Um processo feito, por vezes, "em doses homeopáticas", como afirmou uma das professoras entrevistadas, em gabinetes, ouvindo principalmente os empresários e os "especialistas" nacionais e internacionais contratados para esse fim.

Foi com base nessa lógica que se realizaram as reformas educativas e a implantação das competências no México a partir dos anos de 1990 e que se aprofundaram as reformas na última década nesse país. Foi essa mesma lógica que contribuiu para formatar os novos projetos e planos de curso do CONALEP e de outras instituições de ensino médio e que se tentou impor, em 2014, também ao IPN.

Neste último caso, no entanto, não se esperava que o discurso dos padrões educativos internacionais pudesse enfrentar tanta resistência dos estudantes, que se mantiveram em greve até dezembro de 2014, só voltando às aulas depois que a proposta de adoção de novos planos de curso fosse retirada, a diretora-geral fosse demitida e as autoridades mexicanas se comprometessem, por escrito e ao vivo, pela televisão e demais veículos de imprensa, a democratizar o IPN, mantendo-o a serviço da sociedade, e não exclusivamente do mercado.

\section{CONSIDERAÇÕES FINAIS}

O presente trabalho procurou mostrar o processo de implantação do ensino por competências no México e o papel desempenhado por instituições como o CONALEP e por distintos organismos internacionais para a tropicalização e fortalecimento dessa perspectiva nesse país e em todo o mundo. 
Os aspectos abordados compõem um complexo sistema, que possui uma série de outras vinculações e do qual fazem parte outros organismos internacionais, instituições de ensino e centros de pesquisas. Por questão de espaço e recorte teórico-metodológico, foi privilegiado o debate sobre o CONALEP e o papel da UNESCO, Banco Mundial, OIT e OCDE, enfatizando alguns dos documentos produzidos por esses organismos internacionais sobre a educação profissional e o ensino por competências no México. No entanto, existe uma série de outros documentos, desses e de outros organismos internacionais que poderiam ser analisados. Da mesma forma, existem outras reformas educativas que não foram mencionadas ou que foram pouco exploradas, mas que também compõem esse complexo sistema que visa colocar a educação a serviço da lógica de mercado.

Há muitas décadas, além dos organismos citados, também têm tido grande influência as formulações e recomendações para a educação produzidas pela $\mathrm{Co}^{-}$ missão Econômica para a América Latina e o Caribe (CEPAL) e pela Organização das Nações Unidas (ONU), assim como têm sido estratégicos os empréstimos concedidos ao México e a outros países pelo Fundo Monetário Internacional (FMI) e por bancos de fomento, como o Banco Interamericano de Desenvolvimento (BID). Este último, por exemplo, também foi parceiro do governo do México na implantação das competências a partir da década de 1990, contribuiu financeiramente para a RIEMS, em 2008, e até 2015 continuava financiando projetos para a formação de professores, contratação de assessores, estímulo à qualificação de força de trabalho em projetos de ampliação das parcerias público-privadas e desenvolvimento de novas experiências ligadas à educação por competências e ao estreitamento entre os sistemas educativos e os setores produtivos.

Mesmo com suas realidades, objetivos e projetos específicos, esses diferentes organismos internacionais são parte de um movimento global que estrutura de maneira teórica e prática uma lógica educativa que busca criar um modelo único, baseado em padrões internacionais de formação, certificação e avaliação estruturados por competências, e que encontra nos governos, nas instituições e em intelectuais locais a acolhida necessária para sua adaptação e implantação nos diferentes contextos educativos.

Para os que defendem uma lógica de educação distinta da que se tenta fazer hegemônica em todo o mundo, além de conhecer como se estruturam e se difundem esses modelos educativos propostos pelos organismos internacionais, permanece o desafio de uma maior articulação política e a necessidade de construção de novas formas de luta e resistência em nível local, nacional e global. Com este artigo buscou-se trazer novos subsídios e contribuir nesse sentido.

\section{REFERÊNCIAS}

Aguilar, L. A. El último tramo, 1929-2000. In: GonZalbo, P. E. et al. Nueva historia minima de México. México, DF: Colegio de México, 2013. p. 262-302.

Alberti, V. Manual de história oral. 3. ed. Rio de Janeiro: FGV, 2005.

Banco Mundial. Documento de politica del Banco Mundial: educación técnica e formación profesional. Washington, DC: Banco Mundial, 1992. 
Centeno, J. M. C. El convenio CONALEP-Banco Mundial para la implementación en México de la educación basada en normas de competencia. Ciudad de México: UNAM,1997. Снацноuв, S. Trabalho, lar e botequim: o cotidiano dos trabalhadores no Rio de Janeiro da Belle Époque. 2. ed. Campinas: Editora da UNICAMP, 2005.

Chávez, M. N. Las reformas educativas y su financiamiento en el contexto de la globalización: el caso de México, 1982-1994. Ciudad de México: UPN; PyV, 2000.

Conalep. Valorización del modelo académico de calidad para la competitividad. Metepec: CONALEP; Dirección General; Secretaria Académica, 2012.

. Información estadística de docentes del ciclo 1/1415. Metepec: CONALEP; Dirección de Formación Académica, 2015.

DAle, R. Globalização e educação: demonstrando a existência de uma "cultura educacional mundial comum" ou localizando uma "agenda globalmente estruturada para a educação?” Educação E̋ Sociedade, Campinas: CEDES, v. 25, n. 87, p. 423-460, maio/ago. 2004. Disponível em: <http://www.scielo.br/pdf/es/v25n87/21464.pdf〉. Acesso em: ago. 2016.

Díaz Barriga, Á. El enfoque de competencias en la educación, ¿Una alternativa o un disfraz de cambio? Perfiles Educativos, Ciudad de México: IISUE, v. XXVIII, n. 111, 2006. p. 7-36.

. El docente y los programas escolares: lo institucional y lo didáctico. México, DF: IISUE; UNAM, 2009.

Frigotto, G. A produtividade da escola improdutiva. São Paulo: Cortez, 2006.

García, E. B.; Camacho, A. B.; Álvarez, C. G. Análisis del modelo de educación basada en competencias del Colegio Nacional de Educación Profesional Técnica. Ciudad de México: UNAM, 2014.

Garcia, J. O. El Banco Mundial y su papel en el financiamiento de la educación técnica en México: el caso CONALEP, 1981-1991. Ciudad de México: UNAM, 2012.

Gramsci, A. Os intelectuais e a organização da cultura. 4. ed. Rio de Janeiro: Civilização Brasileira, 1982.

Новsваwm, E. Era dos extremos: o breve século XX - 1914-1991. São Paulo: Companhia das Letras, 1995.

Lundgren, U. P. PISA como instrumento político. La historia detrás de la creación del programa PISA. Profesorado, Granada, Espanha: Universidad de Granada, v. 17, n. 2, p. 15-29, mayo/ago. 2013.

México. Poder Ejecutivo Federal. Plan Nacional de Desarrollo - 1983-1988. México: Secretaría de Programación y Presupuesto, mayo de 1983.

OCDE - Organización de Cooperación y Desarrollo Económico. La OCDE en México. [S.1.]: OCDE, s.d. Disponível em: <http://www.oecd.org/centrodemexico/ laocde/laocdeenmexico.htm>. Acesso em: nov. 2014.

. Acuerdo de cooperación México-OCDE para mejorar la calidad de la educación de las escuelas mexicanas. Paris: OCDE, 2010.

PLÁ, S. Ciudadanía y competitividad en la enseñanza de la historia. México: Universidad Iberoamericana, 2014. 
Portelli, A. Sonhos ucrônicos: memórias e possíveis mundos dos trabalhadores. Revista Projeto História, São Paulo: PUC, n. 10, p. 41-58, dez. 1993.

Ramos, M. N. Trabalbo, educação e correntes pedagógicas no Brasil. Rio de Janeiro: EPSJV, UFRJ, 2010.

. A pedagogia das competências: autonomia ou adaptação? 4. ed. São Paulo: Cortez, 2011.

SACRistán,J. G. La pedagogía por objetivos: obsesión por la eficiencia. Madrid: Morata, 1988. . (Org.). Educar por competências: o que há de novo? Porto Alegre: Artmed, 2011.

Shiroma, E. O. Redes sociais e hegemonia: apontamentos para estudos de política educacional.In: Azevedo, M.; Lara, A. B. M. (Orgs.). Políticas para a educação: análises e apontamentos. Maringá: EDUEM, 2011. p. 15-38. Disponível em: <http://gepeto. ced.ufsc.br/files/2015/03/capitulo-eneida.pdf>. Acesso em: ago. 2016.

Silva, A. L. La historia oral como herramienta para la investigación de la vida escolar cotidiana. In: Congreso Internacional Epistemologías y Metodologías de la Investigación en Educación, 20 i 4. Anais... México, DF: AFIRSE, 2014.

UNESCO - Organização das Nações Unidas para a Educação, Ciência e Cultura. Actas de la Conferencia General - 18 a reunión. v. 1. Paris: UNESCO, 1975.

Weiss, E.; Bernal, E. Un dialogo con la historia de la educación técnica mexicana. Perfiles Educativos, Ciudad de México: ISSUE, v. XXXV, n. 139, 2013.

\section{SOBRE O AUTOR}

Adriano Larentes da Silva é doutor em história pela Universidade Federal de Santa Catarina (UFSC). Professor do Instituto Federal de Santa Catarina (IFSC).

E-mail: adriano.larentes@gmail.com 